\title{
Place of Exercise Echocardiography in Stable Coronary Artery Disease in Sub-Saharan Africa: A Series in Senegal
}

\author{
F. Aw ${ }^{1 *}$, M. B. Ndiaye1, C. M. B. M. Diop ${ }^{1}$, S. A. Sarr' ${ }^{1}$, J. S. Mingou'1, M. T. Diouf ${ }^{1}$, M. M. Ka1, \\ M. Ndiaye1, Hariniaina Ravaoavy1, M. Bodian'1, A. A. Ngaïdé2, M. Dioum³, M. Leye4, \\ A. Mbaye ${ }^{3}$, A. D. Kane' ${ }^{5}$ A. Kane ${ }^{6}$, M. Diao' ${ }^{1}$, S. A. Ba ${ }^{1}$ \\ ${ }^{1}$ Cardiology Department, Teaching Hospital Aristide Le Dantec, Dakar, Senegal \\ ${ }^{2}$ Cardiology Department, General Hospital of Grand Yoff, Dakar, Senegal \\ ${ }^{3}$ Cardiology Department, Teaching National Hospital of Fann Le Dantec, Dakar, Senegal \\ ${ }^{4}$ Research and Training Unit of Thiès, Thiès, Senegal \\ ${ }^{5}$ Cardiology Department, Regional Hospital of Saint Louis, Saint Louis, Senegal \\ ${ }^{6}$ Cardiology Department, Dalal Jamm Hospital, Dakar, Senegal \\ Email: ‘fatoukineaw@yahoo.fr, bambandiaye75@yahoo.fr, sarrsimantoine@yahoo.fr, malickbodian@yahoo.fr, \\ mingoujoseph@gmail.com,damskane@hotmail.com, abdoulkane.cardio@gmail.com, \\ diaomaboury@hotmail.com, serigneabdou2@gmail.com
}

How to cite this paper: Aw, F., Ndiaye, M.B., Diop, C.M.B.M., Sarr, S.A., Mingou, J.S., Diouf, M.T., Ka, M.M., Ndiaye, M., Ravaoavy, H., Bodian, M., Ngaïdé, A.A., Dioum, M., Leye, M., Mbaye, A., Kane, A.D., Kane, A., Diao, M. and Ba, S.A. (2020) Place of Exercise Echocardiography in Stable Coronary Artery Disease in Sub-Saharan Africa: A Series in Senegal. World Journal of Cardiovascular Diseases, 10, 19-29.

https://doi.org/10.4236/wjcd.2020.101003

Received: December 5, 2019

Accepted: January 13, 2020

Published: January 16, 2020

Copyright $\odot 2020$ by author(s) and Scientific Research Publishing Inc. This work is licensed under the Creative Commons Attribution International License (CC BY 4.0).

http://creativecommons.org/licenses/by/4.0/ (c) (i) Open Access

\begin{abstract}
Introduction: Exercise echocardiography is a non-invasive technique that occupies a special place for the detection of stable coronary disease. The main objective of this study was to report our experience and assess our practice in the diagnosis of stable coronaryartery disease. Methodology: We conducted a retrospective study, descriptive over a period of 34 months, from December 1, 2016 to September 30, 2019. All the patients received during the study period for stress echocardiography as part of a suspicion of stable coronary artery disease were included. A total of 100 examinations were completed during the study period. Results: Ninety (90) exams were studied. There were 56 men or a sex-ratio of 1.64. The mean age was of $57.3 \pm 10$ years. Hypertension (31 patients or $62 \%$ ) was the most frequent risk factor. Typical chest pain was noticed in 45 patients (52.3\%). The pre-test probability was intermediate in 77 patients (89.5\%). Echocardiography at rest was normal in 86 patients $(95.6 \%)$. A total of 62 tests were negative (69\%) and $02(2.2 \%)$ were non-contributory. Ten tests (10) of 26 electrical positive tests were associated with segmental kinetics disorders. In the 10 patients who had exercise kinetic disorders, 08 had coronary angiography. It was normal in 04 of them. The positive predictive value of exercise echography was $50 \%$ in our study. In a patient with a negative exercise echocardiography with a high clinical probability of coro-
\end{abstract}


nary disease, the coronary angiography showed a two-vessel impairment with an intermediate lesion of $\mathrm{Cx} 2$ and an intermediate lesion of RCA2. It thus constitutes a false negative. Sensitivity was $80 \%$ in our study. We noticed an incident like non-sustained ventricular tachycardia. Conclusion: Exercise echocardiography is a safe and reliable examination for the diagnosis of stable coronary artery disease. A good selection of patients based on the clinical probability of coronary ischemia should improve our sensitivity. This is even more important in sub-Saharan Africa, where access to coronary angiography is limited.

\section{Keywords}

Exercise Echocardiography, Coronary Artery Disease

\section{Introduction}

Coronary artery disease is an important part of cardiovascular disease. According to the WHO, they are responsible for nearly 7 million deaths per year, or $12.8 \%$ of overall mortality in 2012 [1]. This incidence grows progressively because of more performant diagnostic methods, but also because of the aging population and changes in urban lifestyles, influenced by socio-economic development [1]. In 2017, the CORONAFRIC II study found an incidence of $24 \%$ [2].

In terms of detection for stable coronary artery disease, non-invasive tests occupy an important place. This is even truer in sub-Saharan Africa, where access to coronary angiography is limited due to the lack of cath labs and the price of interventions. Several non-invasive tools can be used. We can cite, besides exercise echocardiography, coroscanner, stress MRI, myocardial scintigraphy.

The advantage of stress echocardiography is that it provides diagnostic and prognostic accuracy similar to that obtained by radionuclide imaging, but at a significantly lower cost, without impact on the environment and without any biological risk to the patient and physician [3].

Besides the diagnostic value, we can talk about the correlation between electrical changes and kinetic disorders. This question has been discussed by many studies which confirmed that segmental kinetics wall disorders were more sensitive and more specific than changes in the ST segment in coronary artery disease detection [4]. Thus, as segmental kinetics wall disorders are both a sensitive and specific marker of early ischemia, exercise echocardiography is therefore more efficient in avoiding false positives.

Echocardiography utility associated with the different stress modalities lies in the possibility to analyse segmental kinetics wall and left ventricular function at rest, then to detect changes in these parameters at the induction of stress (effort or pharmacological) [4]. 
Among the techniques used, effort represents the first choice for patients who are able to exercise [5]. In terms of diagnosis, the sensitivity of stress echocardiography is $80 \%-85 \%$, and its specificity is $80 \%-88 \%$ [6]. In addition to diagnostic value, prognostic value is also important. On one hand, the greater the extent of ischemia in echography is, the worse the long-term prognostic is [7]. On the other hand, a study by the Mayo Clinic, with 5798 patients, shows that in the absence of ischemia during exercise echocardiography, the prognostic at 3 years is very good with the occurrence of few cardiovascular events [8].

Unlike in the West, the data on exercise echocardiography in Africa are poor due to the lack of studies on this topic. In Senegal, only one publication was found in 2011 in which a pharmacological stress (dobutamine) was used [9].

To our knowledge, no studies on exercise echocardiography have been found in West Africa. Today, Senegal is one of the rare countries in sub-Saharan Africa where stress echocardiography is an integral part of the means available in current practice in coronary artery disease care.

The main objective of this study was to report our experience and assess our practice in the diagnosis of stable coronary disease.

\section{Methodology}

We conducted a retrospective study, descriptive over a period of 34 months, from December 1, 2016 to September 30, 2019. Were included, all the patients received during the study period for exercise echocardiography as part of a suspicion of stable coronary artery disease. Patients with incomplete test results were not included in the study.

Data for each patient was recorded on a pre-established data registration form.

The protocol for carrying out the examination was in accordance with the recommendations for the application of exercise echocardiography established by the American echocardiography society [10].

For each patient we studied the epidemiological, clinical data including the estimation of the pre-test probability basing on the evaluation proposed by the European Society of Cardiology in 2013 [11]. We also collected the data from the rest and exercise electrocardiogram on which we were interested in the existence of a depression of at least $1 \mathrm{~mm} ; 0.08 \mathrm{~s}$ after J-point. The rest and exercise echocardiogram was what we were interested in the development of segmental kinetic disorder such as hypokinesis, akinesia or dyskinesia. Figure A1 shows a series of 4-step images performed during exercise echocardiography.

The parameters of the effort such as stopping or not the beta-blockers; the maximum load of the effort in Watts and Mets; the duration of the effort; the maximum frequency reached and the relationship with the maximum predicted heart rate; the reasons for stopping the effort (symptoms, muscular fatigue or dyspnea, elevated blood pressure above $220 \mathrm{mmHg}$ systolic; $85 \%$ maximum predicted heart rate impairment). However, in some cases, the patient could reach 
more than $85 \%$ of the maximum predicted heart rate without any symptoms or electrical or echocardiographic abnormalities, and the examination was continued. The final result of the exam was reported and correlated with coronary angiography data if the patient had benefited from it.

The data collected was entered with Sphinx software version 5.1.0.2. The analysis was performed with the SPSS (Statistical package for Sciences Socials) version 18. The descriptive study was carried out with the calculation of frequencies and proportions for qualitative variables and the calculation of means and standard deviation for quantitative variables.

\section{Results}

A total of 100 examinations were conducted during the study period. Ninety (90) exams were reviewed.

\subsection{Characteristics of the Studied Population}

There were 56 men and 34 women, or a sex-ratio of 1.64. The average age was $57.3 \pm 10$ years. The median age was 58 years.

Hypertension was the most frequent risk factor, with 31 patients accounting or $62 \%$ of cases. It was followed by dyslipidemia in 17 patients or $34 \%$ of cases and obesity in 16 patients or $32 \%$ of cases.

Symptomatology was not specified in 4 patients. Typical chest pain was noted in 45 patients (52.3\%). Nineteen (19) patients or $22 \%$ had atypical pain.

The pre-test probability was intermediate $(15 \%-85 \%)$ in 77 patients $(89.5 \%)$. It could not be calculated in the 4 patients for whom the symptom was not specified. Table A1 shows the general characteristics of the patients.

Rest electrocardiogram was normal in 70 patients or $77.8 \%$.

Of the 20 patients with pathological ECG, 1 had an ST segment depression in 1 patient, 17 had sub-epicardial ischemia in a given territory, and 2 had episodes of ventricular extrasystole.

Echocardiography at rest was normal in most cases, with 86 patients or $95.6 \%$. Other patients had segmental hypokinesia.

The duration of the exercise was recorded in 75 patients. The mean effort duration was $11.7 \pm 5 \mathrm{~min}$ with extremes of $1 \mathrm{~min}$ and $26 \mathrm{~min}$. It was less than 6 min in 27 patients or $36 \%$. The mean maximum load reached was $12.9 \pm 4.9$ Mets.

Of the 34 women listed, two (02) had a maximum load of less than 5 Mets. In men, all 56 patients had a maximum load greater than 7 Mets.

The test was masked in 10 patients, or $11.1 \%$. They had all reached $62 \%$ of their maximum predicted heart rate, so the test was considered maximal in them. Four of them had a positive test or $40 \%$.

The test was maximum unmasked in 59 patients over 80 . Of these 59 patients, 15 patients had a positive test on ECG (25\%) and 6 on echography (10\%).

The most common reason for stopping was muscle fatigue in $46.67 \%$ of cases, followed by maximum predicted heart rate impairment in $22.2 \%$ of cases and 
electrical disturbances in $20 \%$ of cases.

\subsection{Final Results of the Ischemic Tests}

Finally, 26 tests (28.8\%) were positive, 62 (69\%) negative and 02 (2.2\%) non-contributory.

Ten (10) of 26 electrical positive tests were associated with segmental kinetics wall disorders.

Eight of 26 tests were clinically positive with chest pain.

Among the electrical disturbances there were 19 ST segment depression. Elsewhere, 4 patients with ventricular rhythm disorders were considered positive.

A coronary angiography had been performed in 15 patients with positive tests either on clinical plan, electric or echographic.

In the 10 patients who had exercise kinetic wall disorders, 08 had coronary angiography. It was normal in 04 of them. The positive predictive value was then $50 \%$ in our study. Table A2 shows the repartition of patients admitted for ischemic test according to the results of coronary angiography.

In a patient whose exercise echography was negative with a high probability of coronary artery disease, the coronary angiography showed a two-vessel impairment with an intermediate lesion of Circonflexe and an intermediate lesion of right coronary vessel. This is a false negative. Sensitivity was then calculated at $80 \%$ in our study.

In the 15 patients with isolated electrical disorders, 06 had coronary angiography that was normal for each one of them.

We notice done incident of non-sustained ventricular tachycardia, in a 39 years old man with pre-test probability between $15 \%$ and $65 \%$.

The examination noted a large segmental hypokinesis. Coronary angiography revealed a short, tight lesion in segment 1 of the left anterior descending artery.

\section{Discussion}

The objective of this work was to report and assess the results of exercise echocardiography in the diagnosis of coronary artery disease carried out in our structure since 2016 after approximately 3 years of activity.

The main limitation of this study is its retrospective nature explaining the lack of some data. But also, the coronary angiography was missing in some positive patients. This was therefore an obstacle to the evaluation of the sensitivity of the test.

\subsection{Volume of Activities}

Many studies have shown that the use of cardiac imaging has increased considerably in the past years [12] [13]. In the Western countries, this assertion was confirmed by several studies such as Carpegianni et al. [14], where the use rate of exercise echocardiography increased from 0\% to 50\% between 1983 and 2009. 
Our cohort of 100 patients over 34 months appears to be low given the increasing prevalence of coronary artery disease in our regions. But it has increased over the years.

In sub-Saharan Africa, no epidemiological data were found on exercise echocardiography [7]; while it is known that non-invasive tests, especially exercise echocardiography can establish the probability of coronary artery disease with an acceptable degree of certainty [11]. This is even truer in our contexts where access to coronary angiography is limited. In this way, physicians should consider prescribing more exercise echocardiography, given its interest.

This is supported by the ESC 2019 recommendations which call for stress imaging, effort or pharmacological induced, as an initial option if local expertise and availability allow (I, B); Thus, we should see a decrease in diagnostic stress tests in favor of stress imaging if the clinical probability allows it.

\subsection{Clinical Profile of Patients}

In our study, we noticed a clear male predominance with $62.2 \%$ men and $37.8 \%$ women and a sex-ratio of 2.35 . This male predominance is correlated with that observed in coronary artery disease, which varies between $65 \%$ and $80 \%$ in Africa [15].

Hypertension (62\%) was the most common risk factor found in our population. This reflects the data found in the African literature with a prevalence of $59.7 \%$ according to the CORONAFRIC II study [2]. In the West, the same observation was made, Carpegianni [14] found a prevalence of hypertension estimated at $69 \%$ in 557 patients who had benefited from exercise echocardiography.

Exercise echocardiography finds all its great interest in hypertensive patients as hypertension is a disease that is widely under-diagnosed and under-treated, and sometimes revealed by ischemic heart disease [16].

Concerning symptoms, the majority or $51.6 \%$, had consulted for a typical chest pain. We noticed a significant proportion of atypical pain (18.7\%) and asymptomatic patients (14\%). This should encourage a better assessment of pre-test probabilities that could limit inappropriate prescriptions.

\subsection{Probability and Diagnosis of Stable Coronary Heart Disease}

The use of resources is optimal only if pre-test probability, based on clinical data, is taken into consideration before choosing non-invasive tests.

In our series, $8.1 \%$ of patients had a low pre-test probability and should not then benefit from a stress test according to ESC recommendations on stable angina [11]. The major part of patients, $61.6 \%$, had a low intermediate probability between $15 \%$ and $65 \%$, a simple exercise electrocardiographic could be justified in them; however, the recommendations prefer exercise echography if available. The indication of exercise echocardiography was formal in $27.9 \%$ of the patients that had a probability between $66 \%$ and $85 \%$. 
The remaining $2.3 \%$ had a pre-test probability over $85 \%$ and should then benefit from an invasive test.

Practitioners should then no longer base themselves on symptoms alone but rather on the pre-test probabilities proposed by the recommendations for the prescription of any diagnostic test.

In our study, the exercise test was masked in $11.1 \%$ of patients. Bouzas Mosquera [17], during its last study period, found $16.2 \%$ of patients with beta-blockers.

It has been proved that subjects suffering from angina and receiving beta blockers could achieve a higher exercise capacity without showing ischemic signs [18]. This is due to the fact that the use of a $\beta$-blocker decreases both the incremental and maximum heart rate obtained during the exercise, thus limiting the physiological interpretation of the cardiac response and thus the diagnostic accuracy [18]. This could explain the low positive predictive value around $50 \%$. Patients should be better prepared by adjusting their medication, especially beta-blockers that must be stopped 48 hours before the exam.

But the sensitivity found in our work $(80 \%)$ is similar to the values found in the literature which are in the range of $80 \%$ to $85 \%$ [19]. This confirms the diagnostic value of exercise echocardiography which has the advantage of being more available, cheaper and less harmful than other techniques using radioisotopes and which have a similar sensitivity.

In our study, only one minor incident was reported, the non-sustained ventricular tachycardia. There were no major complications (myocardial necrosis, death). The overall complication rate is estimated at $1.1 \%$. Another benefit is its safety, with the largest record of exercise echography complications covering more than 45,000 studies [20].

There were no deceases, eight episodes of resuscitated ventricular fibrillation, five sustained ventricular tachycardias, 51 non-sustained ventricular tachycardias, one myocardial infarction, and 54 unstable coronary syndromes. This test can be considered particularly safe since the overall rate of non-fatal complications is $0.2 \%$.

With a low complication rate, exercise echocardiography is a safe and comfortable exam.

\section{Conclusion}

Exercise echocardiography plays a key role in the known or suspected coronary artery, disease care. To our knowledge this study is a pioneering work in West Africa, no studies on exercise echocardiography have been found. Our low cohort relative to the prevalence of coronary artery disease will continue growing over the years. However, it would be necessary to select patients to preserve the sensitivity of this very useful test that is easy to access and less expensive in our countries where coronary angiography is not frequently accessible. 


\section{Conflicts of Interest}

The authors declare no conflicts of interest regarding the publication of this paper.

\section{References}

[1] World Health Organisation (2018) The Top 10 Causes of Death. http://www9.who.int/gho/mortality_burden_disease/en/

[2] Ticolat, P., Bertrand, E., Barabe, P., et al. (1991) Aspects épidémiologiques de la maladie coronaire chez le Noir Africain: À propos de 103 cas. Résultats de l'enquête multicentrique prospective CORONAFRIC. Cardiologie Tropicale, 17, 7-20.

[3] Sicari, R., Nihoyannopoulos, P., Evangelista, A., et al. (2009) Stress Echocardiography Expert Consensus Statement-Executive Summary: European Association of Echocardiography (EAE) (a Registered Branch of the ESC). European Heart Journal, 30, 278-289. https://doi.org/10.1093/eurheartj/ehn492

[4] Cohen, A., Haddour, N., Ederhy, S., et al. (2010) Échocardiographie de stress: Logistique. In: Cohen, A. and Gueret, P., Eds., Manuel déchocardiographie Clinique, Lavoisier, Paris, 475-499.

[5] Peteiro, J. and Bouzas-Mosquera, A. (2010) Exercise Echocardiography. World Journal of Cardiology, 2, 223-232. https://doi.org/10.4330/wjc.v2.i8.223

[6] Heijenbrok, K., Fleischmann, K. and Hunink, M. (2007) Stress Echocardiography, Stress Single-Photon-Emission Computed Tomography and Electron Beam Computed Tomography for the Assessment of Coronary Artery Disease: A Meta-Analysis of Diagnostic Performance. American Heart Journal, 154, 415-423. https://doi.org/10.1016/j.ahj.2007.04.061

[7] Olmos, L., Dakik, H., Gordon, R., et al. (1998) Long-Term Prognostic Value of Exercise Echocardiography Compared with Exercise 201Tl, ECG, and Clinical Variables in Patients Evaluated for Coronary Artery Disease. Circulation, 98, 2679-2686. https://doi.org/10.1161/01.CIR.98.24.2679

[8] Arruda-Olson, A., Juracan, E.M., Mahoney, D.W., et al. (2002) Prognostic Value of Exercise Echocardiography in 5,798 Patients: Is There a Gender Difference? Journal of the American College of Cardiology, 39, 625-631. https://doi.org/10.1016/S0735-1097(01)01801-0

[9] Mbaye, A., Yameogo, N.V., Ndiaye, M.B., et al. (2011) Dépistage de l'ischémie myocardique par l'échocardiographie de stress à la dobutamine chez le diabétique de type 2 à haut risque cardiovasculaire au Sénégal. Annales de Cardiologie et $d$ Angéiologie, 60, 67-70. https://doi.org/10.1016/j.ancard.2010.07.001

[10] Pellikka, P.A., Arruda-Olson, A., Chaudhry, F.Q., et al. (2019) Guidelines for Performance, Interpretation, and Application of Stress Echocardiography in Ischemic Heart Disease: From the American Society of Echocardiography. Journal of the American Society of Echocardiography, 33, 1-41.e8. https://doi.org/10.1016/j.echo.2019.07.001

[11] European Society of Cardiology, Montalescot, G., Sechtem, U., Achenbach, S., Andreotti, F., Arden, C., et al. (2013) 2013 ESC Guidelines on the Management of Stable Coronary Artery Disease. European Heart Journal, 34, 2949-3003. https://doi.org/10.1093/eurheartj/eht296

[12] Lucas, F.L., Delorenzo, M.A., Siewers, A.E., et al. (2006) Temporal Trends in the Utilization of Diagnostic Testing and Treatments for Cardiovascular Disease in the 
United States, 1993-2001. Circulation, 113, 374-379.

https://doi.org/10.1161/CIRCULATIONAHA.105.560433

[13] Alter, D.A., Stukel, T.A. and Newman, A. (2006) Proliferation of Cardiac Technology in Canada: A Challenge to the Sustainability of Medicare. Circulation, 113, 380-387. https://doi.org/10.1161/CIRCULATIONAHA.105.560466

[14] Carpeggiani, C., Landi, P., Michelassi, C., et al. (2016) The Declining Frequency of Inducible Myocardial Ischemia during Stress Echocardiography over 27 Consecutive Years (1983-2009). International Journal of Cardiology, 224, 57-61. https://doi.org/10.1016/j.ijcard.2016.08.313

[15] Steyn, K., Sliwa, K., Hawken, S., et al. (2005) Risk Factors Associated with Myocardial Infarction in Africa. The INTERHEART Africa Study. Circulation, 112, 3554-3561. https://doi.org/10.1161/CIRCULATIONAHA.105.563452

[16] World Health Organization (2017) A Global Brief on Hypertension. Silent Killer, Global Public Health Crisis. http://www.who.int

[17] Bouzas-Mosquera, L., Peteiro, J., Francisco, J., et al. (2015) Temporal Changes in the Use and Results of Exercise Echocardiography. European Heart Journal-Cardiovascular Imaging, 16, 1207-1212. https://doi.org/10.1093/ehjci/jev068

[18] Gerald, F., Philip, A., Kligfield, P., et al. (2013) Exercise Standards for Testing and Training. A Scientific Statement from the American Heart Association. Circulation, 128, 873-934. https://doi.org/10.1161/CIR.0b013e31829b5b44

[19] Mancini, G.B.J., Gosselin, G., Chow, B., et al. (2014) Canadian Cardiovascular Society Guidelines for the Diagnosis and Management of Stable Ischemic Heart Disease. Canadian Journal of Cardiology, 30, 837-849. https://doi.org/10.1016/j.cjca.2014.05.013

[20] Beckmann, S. and Haug, G. (1999) National Registry 1995-1998 on 150’000 Stress Echo Examinations: Side Effects and Complications in 60448 Examinations of the Registry 1997-1998. Circulation, 100, 3401A. 


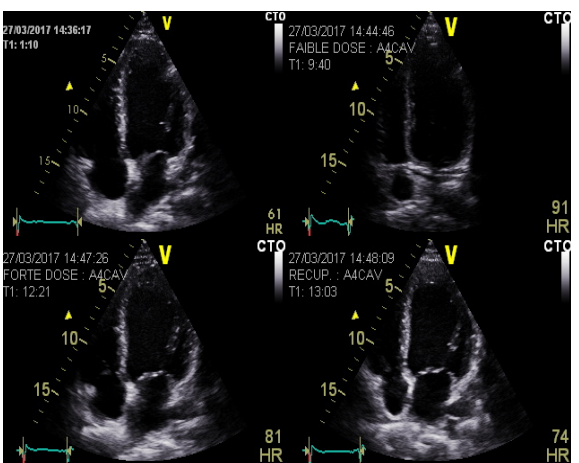

(a)

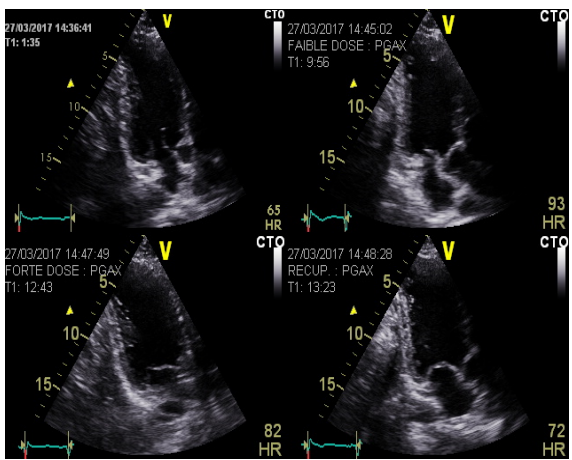

(c)

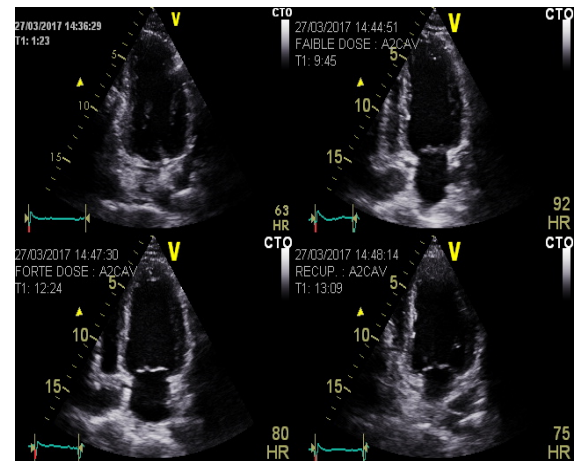

(b)

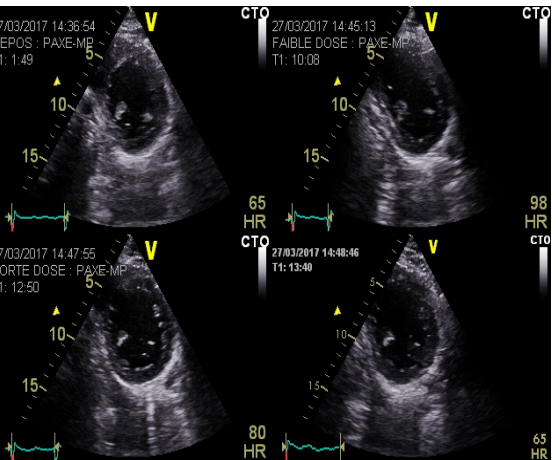

(d)

Figure A1. Series of 4-steps exercise echocardiography images: rest; low effort; maximum effort and recovery: (a) 4-chambers apical view; (b) 2-chambers apical view; (c) 3-chambers apical view; (d) Small-axis left parasternal view. 
Table A1. General characteristics in population of study.

\begin{tabular}{|c|c|c|}
\hline Characteristics & Number & Percentage \\
\hline Meanage (years) & $57.3 \pm 10$ & \\
\hline $50-70$ & 65 & 72.3 \\
\hline Men & 56 & 62.2 \\
\hline Hypertension & 31 & 62 \\
\hline Dyslipidemia & 17 & 34 \\
\hline Obesity & 16 & 32 \\
\hline Typical pain & 45 & 52.3 \\
\hline Atypical pain & 19 & 22 \\
\hline Dyspnea & 9 & 10.5 \\
\hline Symptom-free & 13 & 15.2 \\
\hline \multicolumn{3}{|l|}{ Pretestprobability } \\
\hline$<15 \%$ & 7 & 8.1 \\
\hline $15-65$ & 53 & 61.6 \\
\hline $65-85 \%$ & 24 & 27.9 \\
\hline$>85 \%$ & 2 & 2.3 \\
\hline Normal ECG at rest & 67 & 77.7 \\
\hline Normal TTE at rest & 86 & 95.6 \\
\hline Mean duration of effort (min) & $11.7 \pm 5$ & \\
\hline Masked test & 10 & 11.1 \\
\hline Maximal test & 69 & 76.6 \\
\hline Coronaryangiography & 15 & - \\
\hline
\end{tabular}

TTE: Transthoracicechocardiography.

Table A2. Repartition of patients admitted for ischemic test according to the results of coronary angiography.

\begin{tabular}{cccc}
\hline $\begin{array}{c}\text { Results of test in patients } \\
\text { with coronary angiography }\end{array}$ & Coronaryarterylesion & $\begin{array}{c}\text { Normal } \\
\text { coronaryangiography }\end{array}$ & Total \\
\hline $\begin{array}{c}\text { Segmental } \\
\text { wallkineticsdisorders }\end{array}$ & 04 & 04 & 08 \\
Isolated ECG disorders & 00 & 06 & 06 \\
Normal test & 01 & 00 & 01 \\
Total & 05 & 10 & 15 \\
\hline
\end{tabular}

